Rhode Island College

Digital Commons @ RIC

$5-11-2021$

\title{
Use of High-Fidelity Simulation to Improve Confidence in Military Nurses' Deployment Readiness
}

James F. Jeff

Follow this and additional works at: https://digitalcommons.ric.edu/etd

Part of the Nursing Commons

\section{Recommended Citation}

Jeff, James F., "Use of High-Fidelity Simulation to Improve Confidence in Military Nurses' Deployment Readiness" (2021). Master's Theses, Dissertations, Graduate Research and Major Papers Overview. 381. https://digitalcommons.ric.edu/etd/381

This Major Paper is brought to you for free and open access by the Master's Theses, Dissertations, Graduate Research and Major Papers at Digital Commons @ RIC. It has been accepted for inclusion in Master's Theses, Dissertations, Graduate Research and Major Papers Overview by an authorized administrator of Digital Commons @ RIC. For more information, please contact digitalcommons@ric.edu. 


\section{USE OF HIGH-FIDELITY SIMULATION TO IMPROVE CONFIDENCE IN MILITARY NURSES' DEPLOYMENT READINESS}

$$
\text { by }
$$

\section{James F Jeff}

A Major Paper Submitted in Partial Fulfillment of the Requirements for the Degree of

Master of Science in Nursing

in

The School of Nursing

Rhode Island College

2021 


\begin{abstract}
High-fidelity simulation (HFS) has been shown to be a successful means of skill sustainment and improved confidence across many professions in which human lives are a stake to include the fields of aviation and healthcare. More specifically, HFS technology has displayed efficacy with doctors, nurses, and other advanced practice providers. The flexibility of HFS makes for an ideal educational tool in both professional development and academia. Military medicine could benefit from HFS technology due to the dynamic nature which requires readiness at a moment's notice. The benefit can be significant in the military nursing community due to the frequency of relocation to duty stations and positions that do not allow for frequent use of deployment critical patient care skills. These deployment skills must be carried out by confident military nurses. The functionality of HFS to provide an opportunity to repeat complicated procedures in a safe controlled setting to improve a nurses' confidence is essential (Boling \& Hardin-Pierce, 2016). The purpose of the project was to determine if the use of HFS in addition to traditional online education could improve military nurse confidence with the deployment specific skill of managing a patient with a chest tube. An educational pre-briefing, four simulation scenarios, and a debriefing were implemented and assessed using a modified confidence tool. The project demonstrated improvement in the confidence of all subjects in the assessment, intervention, and evaluation of a simulated patient with a chest tube.
\end{abstract}




\section{Acknowledgements}

I would like to thank my first reader and clinical nurse specialist (CNS) program director Patricia Calvert APRN, GCNS for her patience, expertise, and most of all time to help me through the many trials and tribulations of my research. Without her perseverance and attention to detail I would not have been possible for me to reach the finish line. I would also like to thank Dr. Debra Servello for agreeing to be my second reader despite her duties as acting dean of nursing during a pandemic, and full-time educator. Her experience with my topic and graduate research helped me to produce such an extensive project.

I also want to give a special thanks to the staff at Naval Health Clinic New England and navy medicine region east for their support and authorization of my project. Specifically, I would like to thank Captain Daniel Clark RN MSN, Commander Kendra

Pennington RN, MSN, Ms. Christine Ehlers RN, MSN, and HM2 (FMF) Paul Cannamela USN ret. for their efforts above and beyond the call of duty. I am forever in your debt. 


\section{Table of Contents}

Background/Statement of the Problem ............................................

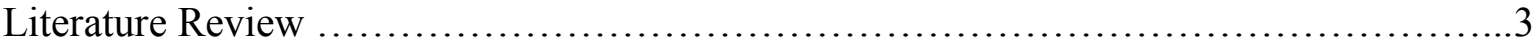

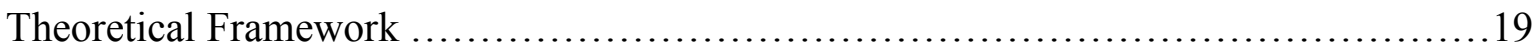

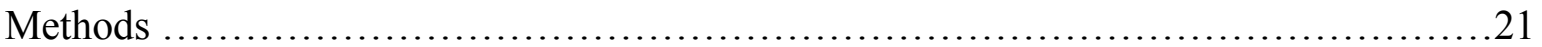

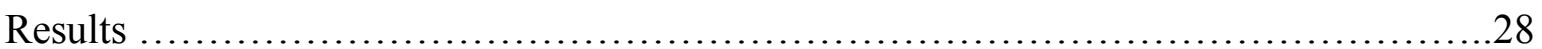

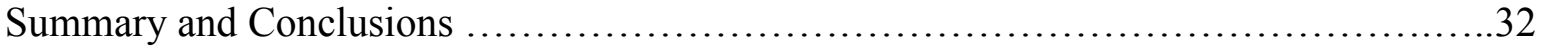

Recommendations and Implications for Advanced Nursing Practice .....................35

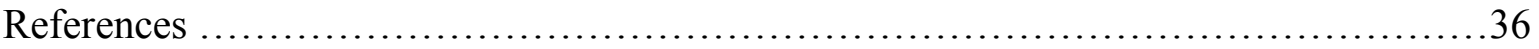

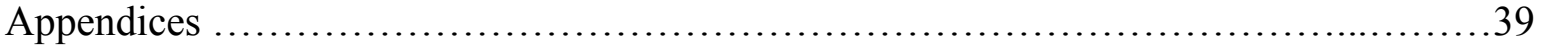


Use of High-Fidelity Simulation to Improve Confidence in Military Nurses’ Deployment Readiness

\section{Background/Statement of the Problem}

United States military nurses are required to perform highly technical nursing care on many platforms. The platforms in which military nurses are deployed include ships, fixed and rotary wing aircraft, and in forward deployed desert settings. Nurses serve in one of three branches of the armed services that include Air Force, Navy, and Army. They serve as active duty at stateside or overseas military treatment facilities (MTF), or as reservists on an as needed basis. The reservists are activated from their civilian healthcare jobs, and the active duty are activated from their MTF's to serve on the platforms. Nurses are often asked to mobilize with only days or weeks of notice. The deployments can last three to twelve months (Ross 2010). Military nurses must maintain a specific set of skills and the confidence to employ them. The nursing skills can include but are not limited to management of traumatic combat injured service members with amputations, head injuries, spinal cord injuries, and other blast related trauma (Ross, 2010).

Beaumont and Allan (2012) recognized that among British military nurses, there is a gap in nurse exposure to the kinds of wartime injuries they can expect to see during military operations. The gap is likely due to the British military model that resembles the United States military reserve model. British military nurses work as a part of the National Health Service (NHS) in civilian hospitals until called upon to serve as a member of a Ministry of Defence Hospital Unit (MDHU). The gap may also be due to the uniqueness of military nursing in which frequent relocations to other MTF's, as well as leadership responsibilities that accompany promotion in rank and draw nurses away 
from the bedside. The leadership responsibilities may include company commander, policy developers, career development expert, or executive leadership in MTF's or on deployed platforms (Ross, 2010).

Beaumont and Allan (2012) suggest that the deficit in skill acquisition and maintenance may result in a lack of deployment readiness. The authors conducted a twostage grounded theory study utilizing postal surveys and in-depth interviews. They received and analyzed 285 postal surveys and conducted twelve in-depth interviews to determine how the employment of military nurses during peace time prepares them for battlefield competence. The authors identified that deployment specific patient care training may improve nurses' perceived competence in the care of traumatically injured soldiers.

Labrague, et al. (2019) conducted a systematic review of studies using highfidelity simulation (HFS) as a means to reduce anxiety and improve nurses' selfconfidence to perform critical skills. The authors defined HFS as the use of human patient simulators and/or standardized patient actors. The authors found that 26 of 29 studies demonstrated improved nurse's self-confidence with a variety of skills to include pediatric, adult cardiac, and electrocardiogram interpretation.

The requirement for military nurses to perform with confidence, and the high success rate of HFS was the impetus for the quality improvement project. The purpose of the quality improvement project was to determine if the use of HFS improved confidence in military nurses' deployment readiness. 


\section{Literature Review}

A literature search was conducted utilizing the Rhode Island College worldwide database, the Cumulative Index of Nursing and Allied Health Literature (CINAHL), and Google Scholar using the following search terms: nursing, high-fidelity simulation, online training, skill acquisition, military competencies, and self-confidence. The literature search included only peer reviewed, full-text journal articles, and those available via an interlibrary loan from 2010 to 2019.

\section{Skill Acquisition in Nursing}

Wilson et al. (2015) explored the process by which nurses obtain bedside skills in response to a phenomenon called the perpetual novice. The authors define perpetual novice as a state in which a nurses' ability to advance from novice to expert is stalled. The researchers further identified that skill competency maintenance is a key to preventing a nurse from becoming a perpetual novice. The study surveyed 42 masters prepared advanced practice nurses (APNs) at two university hospitals in London, Ontario, Canada, in clinical educator, clinical nurse specialist (CNS), advanced practice nurse (APN), or nurse practitioner roles. The researchers conducted an online survey for all 42 participants, followed by 60-minute in-person interviews of ten of those nurses and identified several factors that contribute to being a perpetual novice. The Likert scale survey purpose was to introduce the concept of the perpetual novice and identify strategies that help move nurses from novice to expert. The participants identified some barriers to progression from novice to expert that included poor culture on a given unit, and limited opportunities for learning due to high unit census. The APNs ranked a nurses' ability to maintain skills for infrequent but risky tasks high in importance with a 
mean score of 4.2 out of 5 . They also ranked statements regarding need for skill maintenance as high in importance with a mean score of 4.9 out of 5. Given cultural and time limitations of orientation programs identified by respondents, the study concluded that nursing educators need to move beyond standard educational practices and focus on helping create a culture in which novice nurses do not feel shame and experienced nurses engage in ongoing learning.

Zarifanaiey et al. (2016) studied skill acquisition among undergraduate nursing students. They performed a quasi-experimental study of 40 nursing students that were exposed to critical thinking strategies and simulation or simulation only. The authors created a 20-person control group with simulation only. The 20-person intervention/experimental group included critical thinking strategies, small group discussion and problem-based learning along with simulation. The simulation portion in both groups was a combination of a high-fidelity mannequin and role-playing by the instructors.

Assessment utilized two tools. First, the authors utilized a 34-question multiplechoice questionnaire to assess cognitive ability in five domains to include critical thinking and deductive reasoning called the California Critical Thinking Skills Test form (CCTST). The CCTST evaluation method did not show statistically significant improvement between the two groups. The second evaluation method was scored on the Objective Structured Clinical Examination (OSCE) skills test. The OSCE is ten stations of hands-on skills such as measuring blood pressure and performing wound care. The OSCE results found improvement in the intervention group scores in eight of the ten stations with a mean of $87.35 \%$ compared to $79.9 \%$ in the control group using simulation 
only. Study results indicated that use of simulation combined with critical thinking strategies increased practical learning for the students (Zarifanaiey et al., 2016).

Garner et al. (2018) assessed skill acquisition among 137 first-year medical students performing intravenous (IV) cannulation. Model one consisted of 59 students that attended a medical school that required IV cannulation assessment. The students were provided clinical education on IV cannulation, completed a clinical experience component, and were then assessed in a structured manner by the school. Model two consisted of 79 students that attended a medical school that did not require IV cannulation assessment but did require clinical education on IV cannulation and a clinical experience component. The Mock Objective Structured Clinical Examination (MOSCE) was used to evaluate student performance. MOSCE is a recognized and effective method of measuring simulated clinical skill station performance.

The MOSCE data was collected and each group was evaluated based on the length of time from a student's last hands-on performance of IV cannulation. The authors describe the gap in time since hands-on skills as recency. The recency was divided into four categories that included less than two weeks from use of a skill or completion of competency, two weeks to one month, one to three months, and greater than three months. Model one students had a $73 \%$ higher pass rate on the MOSCE versus $45 \%$ with model two. Model one group contained $82 \%$ with experience within one month of the MOSCE versus $33 \%$ with model two (Garner et al., 2018). The authors determined that the recency of intravenous cannulation, in combination with a structured assessment method, improved the overall scores. The study results aligned with their literature review and found that skills do indeed require recency to ensure competency. 


\section{Online Training}

Online training is often used in undergraduate education, and also as modulebased professional development for practicing nurses. The content can be delivered as video or text and is evaluated by checklists or post-tests to assess nursing knowledge retention. Online training can be tailored for undergraduate nursing students, as well as practicing nurses. Elsevier is one example of an online learning platform with a multitude of professional nursing sub-specialties to include critical care, maternity, pediatrics, and emergency nursing ("Clinical Skills," n.d.).

Kemper et al. (2015) assessed the feasibility of an online training program across many graduate specialties with the implementation of a mind-body skills (MBS) course due to the challenges of educating large interprofessional groups in person. The course contained twelve one-hour modules that covered four general topics of focused attention meditation; positive affect meditation; mindfulness meditation; and guided imagery/hypnosis. The courses were all free and voluntary to the participants. Graduate students in medicine, nursing, nutrition, and social work were recruited from a Midwestern healthcare center. Two hundred and nineteen students were initially included in the study, but only 103 students completed the prospective cohort trial survey. Sixty students completed the full MBS course and the remaining 43 were the control group. The MBS group displayed improvement in five out of nine categories. The categories included perceived stress scale score, mindfulness on the cognitive and affective mindfulness scale (CAMS), self-compassion, confidence in calm compassionate care, brief resilience scale, empathy via perspective-taking, empathy via empathic concern, and compassion on the Santa Clara brief compassion scale (SCBCS). Confidence to provide 
calm and compassionate care was assessed using a 10-item calm, compassionate, care scale from 0 to 100 . Due to a clerical error, only seven of the ten questions items were scored. The mean out of a possible 100 points in the MBS group was 45.1 versus 42.7 in the control group. The overall compassion score via the Santa Clara brief compassion scale (SCBCS). SCBCS is a five-item scale from ranging from one to seven with one representing a compassion statement not at all true to the subject, and seven representing a compassion statement very true to the subject with a possible total score of 35 . The authors found a mean compassion score was higher (30.1) for the MBS group compared to (28.4) the control group.

\section{Online Training in Nursing}

Phillips et al. (2014) conducted a study of online learning modules for palliative care nurses. Their purpose was to evaluate nurse's pain management assessment skills after completing online modules and the resulting pain scores of patients being cared for by those nurses. The study involved 103 nurses and evaluated them with a pre-test (T1) one month before the training, and post-test (T2) six weeks after completion of the intervention. The intervention utilized online learning modules via Qstream. Qstream is a real-time learning platform that has analytic capability and utilizes a repetitive learning style. Nurses' confidence scores related to pain assessment increased across all three categories assessed, which included pain assessment knowledge, pain assessment tool awareness, and pain assessment confidence. Pain assessment confidence saw the greatest increase from 7.4 to 9.3 on a 0 to 10 scale. The authors also completed a retrospective review of patient charts for pain assessment documentation changes after nurses completed the modules. The results identified an increase in the number of completed 
pain assessments by nurses from $54 \%$ for T1 to $69 \%$ for T2. Patient pain score intensity also decreased after the intervention by 1.5 points on a 0 to 10 scale.

Lancker et al. (2016) performed a quasi-experimental study on the effectiveness of e-learning for nursing students completing a medication calculation course. The study randomly selected 189 students from seven colleges who used an e-learning format, and 222 students from six schools who completed a traditional face-to-face didactic course. The results are separated by level of education. Bachelors prepared nurses made up $46.5 \%$ of the total aggregate, and $50.5 \%$ displayed greater improvement with face-to-face learning. The vocational nurses made up $53.5 \%$ of the total aggregate, with an inverse result of $58.2 \%$ showing greater improvement with e-learning. The authors believe overall student improvement in bachelor versus vocational scores is likely due to learner capabilities, and that the overall improvement in face-to-face reinforced the value of inperson education.

Burns et al. (2019) utilized online learning to improve the assessment techniques of nurse midwives. The purpose of the study was to evaluate a midwife's ability to accurately estimate blood loss visually during a water birth. A mixed method design was employed using a pre-test and post-test evaluation tool. Twenty-four nurse midwives were recruited. They were evaluated before and after completion of an online training program. The study's training program consisted of six videos that depicted water births. Subjects were then asked to accurately estimate blood loss in each video. Preintervention blood loss estimates were all below the actual loss depicted in the videos. Improvement in assessment accuracy was identified after midwives viewed the six videos with a reduction in variation of estimated versus actual loss from $32 \%$ to $9 \%$. The study 
also evaluated participants 26 weeks after the initial training and though a decrease in accuracy was noted compared to the initial post-test, there was still a $13 \%$ improvement in blood loss estimates compared to the pre-test scores. The study also asked for feedback from the midwives regarding the effectiveness of the online training and found issues with clarity of content; navigation/access; and low recommendation for further use scores. The small sample group was a significant limitation in the study.

\section{High-Fidelity Simulation Training}

HFS is defined as "...the creation of an event, situation, or environment that accurately reflects a clinical setting where the centerpiece of the environment is an interactive mannequin or standardized patient with the ability to respond (Raman et al., 2019 p. 435)." HFS technology has progressed significantly over the last ten years, and new simulation models have the capacity to exhibit every possible cardiac rhythm, shock state, hemorrhage, and much more. Medical simulators now have the capability to speak, experience a multitude of arrhythmias, hemodynamic instability, hemorrhage, pregnancy, birth, and the ability to receive medications with real time responses for trainees (www.laerdal.com).

Healthcare is not the first specialty to utilize HFS for training and evaluation of skills. The aviation industry has been utilizing some form of simulation since the 1920's. Page (2000) studied the history of flight simulation from the early programs of teaching pilots to fly blind and rely on instrumentation feedback provided to today's high-tech cock pit simulators. The original training was performed in elaborate indoor airplane simulators that would later grow to model high tech aircraft of the modern aviation era. World War II was the impetus for the computer-based electronic simulators of the 1960's 
and 1970's. Over the years, additional cues were added beyond the physical and visual to include motion simulation with mock fuselages on animatronic bases.

\section{Simulation in Nursing Academia}

Nursing schools currently utilize HFS training in combination with both online courses and in-classroom teaching. As a result, much of the available research has focused on the impact simulation has had on the student population.

Morrison and Catanzaro (2010) studied the use of HFS via an assessment of emergency preparedness training. The purpose of the study was to improve undergraduate nurse clinical experiences by placing students in one of two scenarios responding to a bioterrorist exposure. First, students were placed in various responder roles such as a school nurse. Next, students repeated the scenario a second time as a patient. Based on the International Coalition for Mass Casualty Education (INCMCE) competencies, the study focused on items such as critical thinking, assessment, ethics, and communication. Students completed a self-evaluation utilizing a Likert questionnaire that assessed seven concepts of the disaster management simulation on a 1 to 5 scale with (1) strongly agree and (5) strongly disagree. Students responded with $79.5 \%$ strongly agree and $15 \%$ agree regarding the benefit of simulation exercises on their understanding of disaster preparedness.

Venkatasalu et al. (2015) completed a qualitative study that compared education on end-of-life care (ELOC) via a simulation session lasting 60-75 minutes, and a seminar-based teaching session lasting two hours and included video and class discussion. The purpose of the study was to assess the effectiveness of the two learning techniques with first year nursing students. A phenomenographic methodological 
question and answer approach was used to assess thinking and learning of the students. 187 students were divided into eight groups with two groups totaling 48 students selected for the HFS training. The remaining students participated in the traditional two-hour, seminar-based session learning. Twelve students completed the entire study and completed face-to-face interviews. Several themes emerged as a result of the analysis conducted after the interviews. Themes included recognition of death and dying; transitioning death and dying knowledge into practice; preparedness for clinical eventualities; and emotional preparedness.

The study had several self-reported limitations that may directly pertain to any future research. The considerably large attrition may likely be due to the insider effect of first year nursing. The author's described the insider effect as student utilization of social media to talk to each other about their experiences (Venkatasalu et al., 2015).

The study implications and shortcomings may indicate a need to be more cautious about inter-subject contact before all data is collected. Immediate collection of data may have decreased any chance of corruptibility of the responses. The high rate of attrition of subjects in the study may also be related to the subject matter of end-of-life, and therefore assessing student perspectives on the topic before the study began could have been useful (Venkatasalu et al., 2015).

Raman et al. (2019) conducted a quasi-experimental study of HFS that focused on nursing students enrolled in a maternity course. The study compared traditional clinical learning with a combination of traditional clinical and HFS clinical training to improve competency of nursing students in a maternity course. The combination group consisted of 34 hours of simulation training and 101 hours of direct clinical training on the 
maternity units. The traditional learning consisted of direct clinical contact for 135 hours in a university hospital with multiple maternity wards. The study used Kolb's experiential learning theory of concrete experience, reflective observation, abstract conceptualization, and active experimentation to guide the research.

The purpose of the study was to assess the usefulness of HFS as a potential partial substitute for the clinical experience when traditional learning was either not available or not sufficient. According to Raman et al. (2019), deficient learning experiences are often due to a lack of availability of patients, or unwillingness of patients to have students present during births. Students were placed into two categories that included traditional clinical training (TCT) consisting of 40 students, and TCT plus HFS (TCT +HFS) consisting of 34 students. The core competencies measured were critical thinking, communication, assessment, and technical skills. A multiple-choice questionnaire was used to evaluate each group's satisfaction at the end of the simulation. The results of the study found no significant difference among the two groups. Therefore, the authors felt that the $25 \%$ HFS substitution used in the TCT + HFS group is a viable alternative to clinical exposure. The limitations of the study include the small sample size at one university.

\section{Simulation in Professional Nursing Practice}

Fouilloux et al. (2019) completed a pilot study looking at the use of HFS as a training and skill sustainment tool for intensive care unit (ICU) nurses performing Extracorporeal Membrane Oxygenation (ECMO). The purpose of the study was to evaluate the effectiveness of nurse response to ECMO emergencies after completing HFS training. Seven separate training simulations were created with six nurses in each group 
across five ICU units that had ECMO capability. Each scenario had three parts that included pre-briefing and case presentation; simulated scenario completion; and a debriefing period to discuss techniques and gain feedback. Facilitators where outside the room, but available by phone to simulate calls to the intensivist or perfusionist. Participants were evaluated with a twenty-point pre-test and post-test.

The study cohort consisted of 40 nurses in one hospital. The nurses' post-test scores increased from 9.8 to 14.3 out of 20 (Fouilloux et al, 2019). The satisfaction questionnaire, completed at the end of the scenarios, indicated that $95 \%$ of participants expressed a sense of personal improvement. The study identified areas of simulation improvement for future research that included lengthening the debriefing, as well as the need for a safe space to perform the debriefing. Fouilloux et al. (2019) also suggested that training in inter-professional team management for the facilitators would improve quality and realism of the scenarios. Additionally, the authors recommended that there be a degree of familiarity with simulation amongst the facilitators for success with simulations. The study identified an unexpected benefit during the simulation of nurses working as a team 'in situ', which is simulation that is performed in an actual patient environment utilizing the equipment available to them in a real patient scenario. The study does not speak to military nurses specifically, but rather suggests that the use of HFS training can improve nursing skills. The benefit of HFS is particularly true with those skills considered high-risk and low frequency such as ECMO.

\section{Simulation Impact on Nursing Confidence}

D'Souza et al. (2017) studied the effects of HFS on the confidence of 100 undergraduate nursing students in a critical care nursing course in Oman. The authors utilized 
several assessment tools, which included an education practice questionnaire (EPQ), simulation design scale (SDS), and the student satisfaction and self-confidence in learning (SSSCL) questionnaire to assess the effects of simulation on confidence in critical care nursing. All 100 students were exposed to the same interventions to improve learning throughout the semester. The interventions included videos and HFS. No lecture was provided prior to the video and simulation interventions. The scenarios included myocardial infarction and cardiac arrest; trauma and shock; and diabetic ketoacidosis and hyperglycemia. The HFS utilized the Laerdal SimMan 3G. The 100 students were divided in 10 groups and completed a 15-minute HFS scenario followed by a 20-minute debriefing. Overall average satisfaction mean with simulation design was higher (88.6\%) versus video education $(64.5 \%)$ with a $t$ value of 2.20 and a $p$ value of 0.19 . Self-confidence mean after simulation was higher (87.6\%) versus video education control group (66.9\%). Post-test knowledge and performance improvement was displayed in all scenario topics on a 0-20 assessment scale. The scenarios included shock and trauma with 16.0 out of 20 for HFS versus 11.4 out of 20 for video; myocardial infarction and cardiac arrest with 15.9 out of 20 for HFS, versus 10.1 out of 20 for video; and diabetic ketoacidosis and hyperglycemia with 17.1 out of 20 for HFS versus 12.9 out of 20 for video. The subjects' overall performance compared to each other trended along demographic lines with higher scores among those with higher grade point average (GPA), previous HFS experience, and older age.

Connors et al. (2017) conducted a quasi-experimental study of 26 associate degree nursing students receiving education on providing spiritual care. The researchers utilized a competence and confidence tool to assess improvement between a control group with traditional classroom learning of spiritual care, and the study group with the addition of 
simulation scenarios. A ten-question Likert survey was utilized and scored 1 (strongly agree) to 5 (strongly disagree) regarding a nurses' role in spiritual care of patients (Hoffert, et al. 2007). The authors utilized three separate interventions. Students were first provided traditional classroom lecture on spiritual care. Next, each student was tasked with completing a spiritual assessment on a patient from a clinical experience. Lastly, students completed a spiritual assessment with patient actors in a simulation. The simulation components included a pre-simulation exercise, simulation, and a debriefing. Greatest improvement was found after simulation completion posttest $(\mathrm{t}=5.65, \mathrm{P}<.001$; $\mathrm{d}=0.93$ ). The authors concluded that the simulation activity produced an improvement in students' overall perceived ability to provide spiritual care to patients.

Labrague et al. (2018) completed a systematic review of studies that looked at nursing student's anxiety and self-confidence. Several studies in the review did not employ a standardized tool, but rather student feedback regarding self-confidence and/or anxiety. Ten studies utilized the student satisfaction and self-confidence in learning (SSSCL) or the national council for state boards of nursing (NCSBN) self-confidence tool. The review defined HFS as the use of human patient simulators and/or standardized patient actors. The control groups included traditional lectures, along with low or medium fidelity simulation. The conclusions of the systematic review were divided into effects of HFS on student anxiety and confidence. Twenty-six out of 35 studies involving 2,489 subjects found that HFS improved student confidence. Several studies were randomized control trials (RCT) and identified improved confidence in areas of physical assessment, cardiac emergencies, and maternity patients. Each RCT compared HFS to traditional classroom learning. Additionally, the authors identified that 
simulation has a place in enhancing nursing education, reducing anxiety, and improving student confidence by bridging the gap between lecture and practice.

Singer, et al (2013) was cited in the Labrague (2018) systematic review for work assessing 40 first-year residents with no medical intensive care unit (MICU) experience, compared to 27 third-year residents with MICU experience. The first-year residents were exposed to simulation training in the management of ventilated patients. The first-year residents outscored the third-year residents utilizing a knowledge and patient management tool for ventilated patients $91.3 \%$ to $80.9 \%$ (Singer et al., 2013). The authors deduced that the improvement in the first-year residents was due to their simulation experience. Pascual et al. (2011) was also cited by Labrague (2018) for their study involving 12 nurse practitioner and physician assistant subjects who were exposed to five simulation scenarios of critical care emergencies. Participants displayed a 5\% improvement in knowledge and an 8\% improvement in confidence over a control group that consisted of four critical care fellows whom did not complete the simulation scenarios (Pascual et al., 2011).

\section{Military Nurse Readiness for Deployment}

Ross (2010) studied military nurse deployment readiness competencies across the tri-services. She identified that (1) military nurses must be able to deploy at a moments' notice; (2) all military nurses regardless of specialty must be ready for deployment to combat zones, humanitarian missions, and peace-keeping missions; (3) nurses must be prepared for multi-trauma combat injuries. Military nurse competence is determined by the Readiness Estimate and Deployability Index (READI), as well as operational nursing competency checklists that are completed during patient care. The author did not elaborate 
on the specifics of the instruments beyond their use to determine the level of competence, confidence, and ability to create a profile of skills for military nurses that included operational patient care and leadership.

Ross (2010) identified areas of competence to include nursing practice, military service, and leadership. The nursing practice portion carries a significant challenge outlined above. In addition to the multi-trauma injuries, military nurses also face cultural challenges along with potential exposure to biological, chemical, and radiologic weapons of war. The nurses' capability to perform patient care while donning the protective equipment for these exposures presents additional challenges to communication and physical abilities.

A military nurses' service competency focuses on their knowledge of a given mission, ability to follow military protocols in a given situation, knowledge of regulations, and most importantly patient movement/transport (Ross, 2010). The patient movement process is key for military nurse to grasp given the challenges in a military theater to include combat operations, weather, fuel availability, and the finite resource of skilled medical staff and aircraft for evacuation. The nurses that perform the patient movements are asked to do so under dangerous conditions with limited technology (Ross 2010).

Lastly, Ross (2010) explains the intricacies of the leadership competencies. Military nurses are expected to advance through the ranks and obtain greater responsibility. Nurses in military leadership must understand battlefield operations and patient care, but also the continuous readiness process for those not deployed, and the capability of stateside healthcare institutions. 
Abelsson and Lundberg (2019) conducted a survey of 26 Swedish military professions to assess their self-rated perception of knowledge after simulation. The study professionals included physicians, nurses, and medics. Nurses scored the highest in eight of ten categories on a Likert scale from strongly disagree (1) to strongly agree (5). The scores were based on the subject's self-rated perceptions of their knowledge regarding their preparation to care for a real-life trauma patient and were compared to the other medical professions. The self-perception categories and scores included medical and ethical knowledge (nurses-4.0; doctors-3.4; medics-2.6), medical experience (nurses3.55; doctors-2.6; medic-1.9), and ethical experience (nurses-3.64; doctors-3.4; medics2.0). The study's findings suggest that nurses often came into contact with patients in their area of specialty in their civilian jobs. Therefore, when called upon to serve, they felt more prepared to care for battlefield patients. The study also identified that nurses have greater knowledge obtained from hands-on experience in comparison to other medical specialties.

Military nurses face challenges due to their inability to gain exposure to the variety of patients they may encounter in a deployment setting (Beaumont \& Allan, 2012). The feasibility of including simulation in deployment readiness may provide support for implementation of simulation scenarios into the military nurses' training program. Ultimately, simulation could provide an alternative way for military nurses to obtain the hands-on skills needed to be successful, but also feel confident to do so.

The purpose of the quality improvement project was to determine if the use of HFS increases nurses' confidence in the management of chest tubes during military deployment. 


\section{Theoretical Framework}

The quality improvement project utilized Kolb's experiential learning theory and the Logic model. The Logic model will be discussed in the methods section and will guide the structure of the project.

\section{Experiential Learning Theory}

Kolb's model originated in the disciplines of psychology and education and is a mid-range theory that is operationally focused. Elements of Experiential Learning Theory (ELT) are divided into four steps: a concrete experience, a reflective observation, an abstract conceptualization, and active experimentation (Kolb \& Kolb, 2019).

ELT postulates that in order to learn new information, a learner is presented with a problem that violates their previous understanding. Learning takes place when the learner is able to change and/or adapt previous knowledge (Kolb \& Kolb, 2019). First, concrete experience involves a challenge to previously held beliefs that the learner has been exposed too. Next, abstract conceptualization includes the learner's interpretation and understanding of the challenge by reviewing past experiences and knowledge. Both the concrete experience and abstract conceptualization steps are how the learner receives and processes information regarding the challenge according to Kolb and Kolb (2019). Third, the challenge is processed into new learning and a solution is created via reflective observation. Finally, the learner takes their solution and tests via active experimentation. As the learner encounters additional challenges and creates solutions throughout their life, the helical nature of ELT allows each learned experience to build on the next and be used to problem solve future challenges. 
The ELT steps are incorporated in the quality improvement project. The concrete experience was reflected in the care of a simulated patient with a series of complications in a deployed setting to include chest tube air leak, chest tube dislodgement, and chest tube draining system that is knocked to the floor. The reflective observation included comparison of previous experience and/or knowledge from a computerized online training platform. A combination of both previous, and newly learned knowledge and newly gained experience comprised the abstract conceptualization during debriefing. The learners then incorporate their experiences from the project with future deployment experiences to fulfill the active experimentation portion. 


\section{Methods}

\section{Purpose}

The purpose of the quality improvement project was to determine if the use of HFS increases nurses' confidence in the management of chest tubes during military deployment.

\section{Design}

The design of the quality improvement project was a pre-test, post-test design with the intervention of an HFS confidence building exercise in the management of chest tubes.

\section{Sample and Site}

The convenience sample consisted of ten military nurses stationed at Naval Health Clinic New England (NHCNE), which functions as a hub for three additional satellite clinics that are head-quartered in Newport, RI. Nurses participated in required annual deployment skills review at the naval education center's simulation lab also located in Newport, RI.

\section{Procedures}

The quality improvement project was guided by the Kellogg Logic Model. The model, designed in 1998, provides a framework to encompass key aspects to ensure completion of a project or program (W. K. Kellogg, 2004). The model has several steps that must be completed in consecutive order to achieve the desired outcomes. The first step in Kellogg's model is to consider resources and inputs. The resources include human resources, as well as physical or financial resources to complete a project. Second, activities are the means by which the project will set out to solve a problem or 
improve the quality of work. Kellogg's model refers to the first two steps as the planned work. Third, the outputs are the successful completion of the first two steps. Fourth, the outcomes are the measurable improvements that have resulted for the project in the short term. Lastly, the impact that the project outcomes will have on a given population. (see figure 1). A discussed of the steps regarding the quality improvement project is next.

\section{Figure 1}

The Logic Model

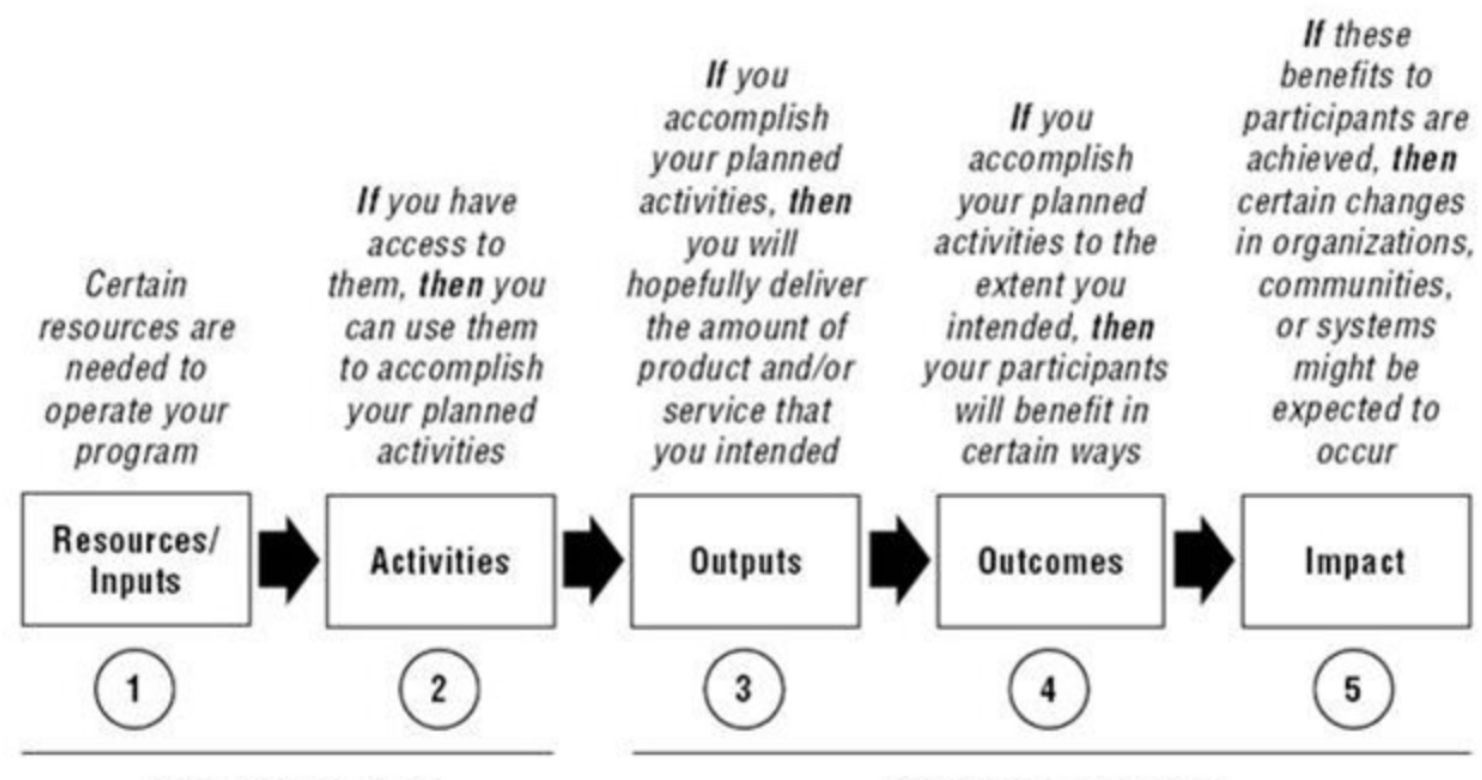

Your Planned Work

Your Intended Results

Application of the Logic Model. The logic model guided the development of the quality improvement project to determine if the addition of simulation in addition to traditional online learning modules increases nurses' confidence in the management of chest tubes during military deployment.

Permission and approvals. Permission was granted for the use of the naval education center's SIM Man 3G and the simulation support staff for performance of the project. Approval for the project was conducted utilizing the naval educational 
partnership agreement (EPA). The EPA was reviewed and authorized by Rhode Island College legal affairs and the navy's Bureau of Medicine and Surgery (BUMED). Approval for the project was sought from Rhode Island College Institutional Review Board (IRB).

Inputs. The inputs or resources needed for the quality improvement project included the participation of ten navy nurses project to form the convenience sample. Physical resources for the project included a SIM Man 3G, simulation support staff, chest tube drainage system, and dressing supplies. The support of nursing leadership at NHCNE was required to assist with availability of nurses, transportation of nurses to the simulation lab, and use of the simulation lab.

Activities. Hicks, et al (2009) published a research brief for the National Council of State Boards of Nursing (NCSBN). The brief's simulation self-confidence instrument (Appendix A) designed to assess confidence with cardiac, respiratory, mental status, shortness of breath, and neurological events, was modified for the specific nursing skill of chest tube management (Appendix B). The scale is divided into recognition/assessment of signs and symptoms, appropriate intervention, and evaluation of intervention for each event. The scale is scored (1) not at all confident to (5) very confident. The modifications to the tool (Appendix B) included a stable chest tube patient, a chest tube patient that has an air leak, a chest tube patient that has become dislodged, and a chest tube patient whose drainage system has been knocked to the floor. Also, a debriefing was conducted after the post-confidence survey to ensure each group of subjects was provided the opportunity to reflect on their performance and their 
experience without impact to their responses. Finally, the analysis of the data was completed and is presented in the results section of this paper.

Program content and outcomes. The simulations scenarios (Appendix C) as well as the pre-briefing materials (Appendix D) were based on the Elsevier online learning tutorials for chest tube management, currently used by the United States navy for nursing competency assessment. Participants completed the Elsevier online modules prior to completion of the chest tube management simulation. The scenarios were constructed to illicit improved confidence with four key chest tube management skills. 1) care of a stable patient with a properly functioning chest tube; 2) care of a patient who has a leak in the chest tube management system; 3) care of a patient who has their chest tube drainage system knocked to the floor; 4) care of a patient with a chest tube that has become dislodged. Each of the scenarios was a discrete simulation experience. The nurses participated in each scenario in teams of two and completed a debriefing with the facilitator at the end. The facilitator was a master's prepared navy nurse educator with experience in creating and running simulations. Participants were required to utilize the knowledge acquired during the online tutorial, as well as previous chest tube experience in practice.

Outputs. The outputs for the quality improvement project included the confidence gained as a result of the simulation intervention, as well as the pre-briefing and debriefing. The simulation scenarios were developed using evidence-based practice, Elsevier educational materials, and the military's clinical practice guidelines (CPG). Outputs also included the pre-test and post-test results from the modified NCSBN selfconfidence tool. 
Outcomes. The desired outcomes for the quality improvement project are the perceived improved in self-confidence that was measured via the modified NCSBN instrument. The outcome of self-confidence in the management of chest tubes was measured in short-term effects in accordance with the Logic Model. Short-term goals were determined based on perceived improvement in self-confidence after the course. Additionally, the long terms goals included military nurses' consistent demonstrated confidence to perform the required chest tube management while deployed.

Impacts. The project has far reaching impacts to include greater HFS adaptation into the military training process with continued assessment of nurses' confidence. The confidence measures could be used to determine army, navy, and air force nurses' confidence to carry out deployment orders to care for traumatically injured patients in multiple settings. The project has the potential to include confidence as the key partner to competence when assessing military nurse readiness.

Assumptions and external factors. Several assumptions were made during the creation of the process improvement project. The assumptions included a willingness of military nurses to participate in a program that is designed to improve their confidence to carry out required nursing deployment skills. Assumptions were also made that the nurses participating in the project were willing to complete a debriefing, as well as the pretest posttest in the form of the modified NCSBN tool. External factors included the degree of support from the navy clinic, availability of the SIM Man 3G, and the ability for the nurses to travel from four remote clinics to Newport, RI to participate in the project. 


\section{Measurement}

A 10-question Likert scale pre/post-test was used to measure self-reported confidence levels with assessment and intervention of a patient with a chest tube, using the modified NCSBN (Appendix B). Pre-test surveys were anonymously completed and collected into a designated folder prior to the educational session. Post-test surveys were also anonymously completed and collected in a designated folder at the completion of the debriefing. Surveys were stored in a secure cabinet in the education and training department office after collection.

\section{Challenges and opportunities}

Institutional resources were readily available from NHCNE to facilitate the quality improvement project. Classroom space was allocated for the pre-briefing, debriefing, and a separate space for simulation. Education support staff was available to assist where needed and ensured a safe disinfected space. Anticipated challenges included the number of participants and the potential for staffing shortages and quarantine requirements due to the Covid-19 pandemic. Staff were masked and socially distanced for the entire project without complication. Travel restrictions did however limit participation from clinics of NHCNE that were out of state therefore limiting the $\mathrm{N}$ to 4 .

Alternate educational days were considered, but the potential risk of exposure and continued travel restrictions prevented additional sessions. The time constraints prevented additional participants. Lastly, no demographic data regarding years of experience as a nurse, years in the navy, and number of deployments was collected. 


\section{Ethical considerations}

The project was reviewed and approved via an Educational Partnership Agreement (EPA) between Rhode Island College and the United States Navy. The project was then reviewed by the Rhode Island College Institutional Review Board (IRB) and determined to be a quality improvement project. Subjects in the project were informed that they could withdraw from the project at any time during the pre-briefing, simulation, or debriefing. Additionally, no personal information was collected from any of the participants.

Next, the results will be discussed. 


\section{Results}

A total of four out of a possible ten nurses attended the HFS simulation session. All four nurses completed both the pre-test and post-test modified NCSBN confidence tool $(\mathrm{N}=4 ; 100 \%)$. Participants rated confidence on a scale 1 , not at all confident to 5 , very confident. No questions were left unanswered by any of the participants. The overall pre-test mean score was 3.375 which indicated an overall confidence with the tasks in the survey of $67.5 \%$. The post-test mean score was 4.5 which indicated an overall confidence with the tasks in the survey of $90 \%$. The data represented a $22.5 \%$ increase after the completion of the chest tube management educational and simulation activities.

The pre-test and post-test mean scores are compared side by side for each of the 10 questions in Table 1 and Figure 2 below. The questions are grouped into three categories. Questions 1 through 4 are related to the subject's confidence with recognizing signs and symptoms of a patient with a chest tube. Questions 5 through 7 are related to the subject's confidence with hands on interventions to aide a patient with a chest tube. Questions 8 through 10 are related to the subject's confidence with evaluating their interventions for a patient with a chest tube.

The highest initial confidence prior to beginning the simulation, was on question 1 which asked, "How confident are you that you can recognize signs and symptoms of a stable patient with a chest tube." The question is related to a stable patient so the mean pre-intervention score of 4 or moderately confident was expected. The lowest initial confidence scores were for questions 5,8 and 9 with a mean of 3, or somewhat confident. Question 5 pertained to confidence to manage a patient with chest tube that has an air leak, while 8 and 9 pertained to confidence with evaluation of troubleshooting 
interventions for a patient with a dislodged chest tube, and a patient whose chest tube drainage system had been knocked to the floor.

The post-test means scores with the greatest improvement in confidence of $30 \%$ over the pre-test was for questions 5 and 7 that pertain to interventions for a patient with an air leak in their chest tube, and interventions for a patient whose chest tube drainage system was knocked to the floor. Also, the same improved confidence was found for question 9 related to evaluation of interventions for a patient with dislodgement of their chest tube. The questions with the least improvement of only $10 \%$ were questions 1 and 4 each of which had the two highest pre-test confidence scores (4/5 and 3.75/5 respectively).

The survey category pertaining to nursing interventions displayed the greatest post-test improvement in confidence were assessed via questions 5 through 7 with an increase of $27 \%$ (3.25 to 4.6). The next highest confidence improvement was for questions 8 through 10 which related to evaluation of the effectiveness of nursing interventions for patients with chest tubes with $26 \%$ (3.1 to 4.4$)$. Lastly, the area with the least improvement in confidence with chest tube management reflected in questions 1 through 4 with a $14 \%$ increase $(3.7$ to 4.4$)$. The high initial pre-test confidence levels with the nursing skills of patient assessment likely resulted in low improvement in the post-test score. 


\section{Table 1}

Mean Confidence-Scale Ratings of Confidence

\begin{tabular}{|c|c|c|}
\hline Question & $\begin{array}{c}\text { Pre-Test } \\
\text { Mean }\end{array}$ & Post-Test \\
\hline $\begin{array}{l}1 \text { How confident are you that you can recognize } \\
\text { signs and symptoms of a stable patient with a } \\
\text { chest tube? }\end{array}$ & 4 & 4.75 \\
\hline $\begin{array}{l}2 \text { How confident are you that you can recognize } \\
\text { signs and symptoms of a patient with an air leak in } \\
\text { their chest tube management system? }\end{array}$ & 3.5 & 4.5 \\
\hline $\begin{array}{l}3 \text { How confident are you that you can recognize } \\
\text { signs and symptoms of a patient with a dislodged } \\
\text { chest tube management system? }\end{array}$ & 3.5 & 4.5 \\
\hline $\begin{array}{l}4 \text { How confident are you that you can } \\
\text { appropriately intervene for a patient with an air } \\
\text { leak in their chest tube management system? }\end{array}$ & 3.75 & 4.25 \\
\hline $\begin{array}{l}5 \text { How confident are you that you can } \\
\text { appropriately intervene for a patient with an air } \\
\text { leak in their chest tube management system? }\end{array}$ & 3 & 4.5 \\
\hline $\begin{array}{l}6 \text { How confident are you that you can } \\
\text { appropriately intervene for a patient with a } \\
\text { dislodged chest tube? }\end{array}$ & 3.5 & 4.5 \\
\hline $\begin{array}{l}7 \text { How confident are you that you can } \\
\text { appropriately intervene for a patient whose chest } \\
\text { tube management system has been knocked over? }\end{array}$ & 3.25 & 4.75 \\
\hline $\begin{array}{l}8 \text { How confident are you that you can evaluate the } \\
\text { effectiveness of your interventions for a patient } \\
\text { with an air leak in their chest tube management } \\
\text { system? }\end{array}$ & 3 & 4.25 \\
\hline $\begin{array}{l}9 \text { How confident are you that you can evaluate the } \\
\text { effectiveness of your interventions for a patient } \\
\text { whose chest tube has been dislodged? }\end{array}$ & 3 & 4.5 \\
\hline $\begin{array}{l}10 \text { How confident are you that you can evaluate } \\
\text { the effectiveness of your interventions for a patient } \\
\text { whose chest tube management system has been } \\
\text { knocked to the floor? }\end{array}$ & 3.25 & 4.5 \\
\hline
\end{tabular}




\section{Figure 2}

Pre-test and Post-test Confidence Survey Results

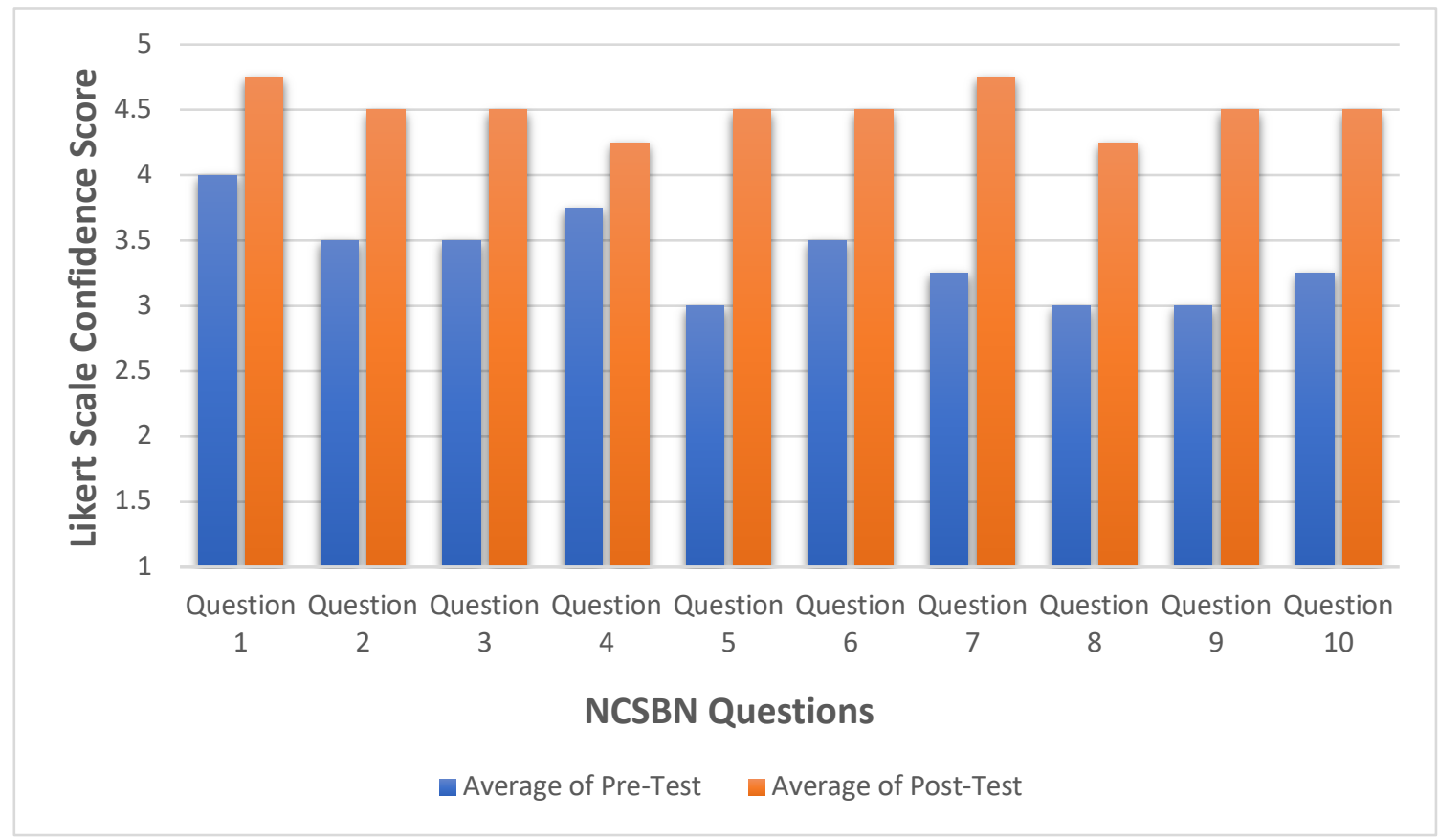

Note. This figure demonstrates the improvement in post-test mean scores for each NCSBN survey question.

\section{Dissemination}

The project findings were analyzed using descriptive statistical analysis and presented to identify the confidence outcomes after the HFS project intervention via mean Likert scale scores. Results were disseminated to the senior nurse executive at NHCNE, Navy Medicine East Region, and presented to the Nurse Executive Committee (NEC) at NHCNE. The quality improvement project and content are applicable to many other commands throughout navy medicine in which nurses have limited patient care exposure. Lastly, the project findings were presented at the Rhode Island College graduate symposium.

Next, the summary and conclusions will be discussed. 


\section{Summary and Conclusions}

The use of HFS had a significant impact on the confidence of military nurses as they practice the deployment skill of patient management for chest tubes. Improvement was identified with assessment, intervention, and evaluation of interventions related to patients with chest tubes. Specifically, the results from the NCSBN survey indicate that the critical tasks of nursing intervention and evaluation of intervention for the life-threatening events of chest tube dislodgement, management of a leak in the system, and damage to the drainage system were all improved with the use of the projects simulation experience. Therefore, HFS was a useful means of providing hands education to military nurses that will be used confidently in practice when needed.

The results of the quality improvement project are a strong indicator of future success with use of HFS and confidence measures for other deployment nursing skills such as care of patients with burns, traumatic amputations, and head injuries. The ability of HFS to simulate a variety of patient conditions, as well as it's versatility with hands-on assessment could support military nurses' readiness for deployment. Additionally, the wide availability of HFS mannequins across the Department of Defense (DOD) healthcare system provides for the opportunity to make expansion of the quality improvement project a reality.

Logistical challenges might be confronted in attempting to scale up HFS predeployment training, such as cost for travel, staff shortages, and the COVID-19 restrictions. Also, each branch of the DOD healthcare system has different rules, regulations, and budgets to consider. The navy's current use of simulation technology, as well as their robust education and training infrastructure make for the ideal branch to 
consider the benefits of HFS for improved nurse confidence with a greater number of deployment skills.

The purpose of the quality improvement project was to determine if the additional of HFS to the standardized Elsevier online training would improve nursing confidence in the assessment and management of patients with chest tubes. The results of the project indicate that indeed the use of HFS does improve confidence. The use of the modified NCSBN confidence demonstrated increased confidence in all 10 performance skills.

Next, the limitations of the project will be discussed. 


\section{Limitations}

The simulation session was only offered once due to Covid-19 travel restrictions, scheduling conflicts, and HFS mannequin availability. Additionally, the willingness of only four nurses to participate despite ten potential subjects impacted the n. Due to department of defense (DOD) restrictions for non-military research, the lack of demographic data to include age, years of experience as a nurse, and number of deployments was not collected. The demographic data could have provided clarity on the initial pre-test confidence scores for some participants, as well as the post-test confidence.

The quality improvement project was completed at a clinic with a limited number of military nurses. A command with a larger population of nurses in nonpatient care areas may have yielded a larger $\mathrm{n}$ and lend greater validity to the improved confidence percentage. Lastly, the project only focused on chest tube management. The potential for the modified NCSBN tool to be expanded to include a variety of deployment assessment skills over a several days course could provide a better assessment of overall deployment readiness confidence among military nurses.

Next, the recommendations and implications for advanced nursing practice will be discussed. 


\section{Recommendations and Implications for Advanced Nursing Practice}

The literature review indicated a significant gap in military nurse confidence with deployment skills, and that HFS can enhance that confidence. The APRN is key to the innovation of effective educational interventions for staff and colleagues. The NCSBN modified tool was an effective tool that was developed and implemented to close the confidence gap for military nurses regarding the management of patients with chest tubes.

The Nurse Executive Committee provided the opportunity to explain the project results and potential impacts to all nurses at the command. Several members of the committee are clinical nurse specialists who recognized the importance of improving both confidence and competence for those nurses that are stationed at clinics or other administrative duties. Additionally, the senior nurse executive at NHCNE acknowledged the value of the project to navy nursing practice and sent a request to navy medicine region east leadership to share details of the project and how HFS can be used to improve readiness for deployment.

Lastly, the knowledge and skill to use HFS to the fullest extend was key to the success of this project. APRNs should be strongly encouraged to seek out and obtain training to use HFS technology. As mentioned in the literature review, nursing academia has embraced HFS in order to augment the clinical experience of students with promising results. HFS has grown to be an essential tool in healthcare and therefore a critical need for the APRN. 


\section{References}

Abelsson, A., \& Lundberg, L. (2019). Military medical personnel's perceptions of treating battle injuries. Journal of Military and Veterans Health, 27(2), 10.

Beaumont, S. P., \& Allan, H. T. (2012). Supporting deployed operations: are military nurses gaining the relevant experience from MDHU's to be competent in deployed operations? Journal of Clinical Nursing, 23, 65-74. http://dx.doi.org/10.1111/j.1365-2702.2012.04315.x

Boling, B. \& Hardin-Pierce, M. (2016). The effect of high-fidelity simulation on knowledge and confidence in critical care training: an integrated review. Nurse Education in Practice, 16, 287-293. http://dx.doi.org/10.1016/j.nepr.2015.10.004

Burns, E., Hunter, L., Rodd, Z., MacLeod, M., \& Smith, L. (2019). Developing and evaluating an online learning tool to improve midwives' accuracy of visual estimation of blood loss during water birth: An experimental study. Midwifery, 68, 65-73. http://dx.doi.org/10.1016/j.midw.2018.10.004

Connors, J., Good, P., \& Gollery, T. (2017). Using innovative teaching strategies to improve nursing student competence and confidence in providing spiritual care. Nurse Educator, 42(2), 62-64. http://dx.doi.org/10.1097/NNE.0000000000000301

D'Souza, M. S., Venkatesaperumal, R., Chavez, F. S., Parahoo, K., \& Jacob, D. (2017). Effectiveness of simulation among undergraduate students in the critical care nursing. International Archives of Nursing and Health Care, 3(4), 1-8. http://dx.doi.org/10.23937/2469-5823/1510084

Fig. 1. Kellogg Foundation, W. K. (2004). W. K. Kellogg Foundation logic model development guide. Retrieved from 
https://www.bttop.org/sites/default/files/public/W.K.\%20Kellogg\%20LogicModel . $\mathrm{pdf}$

Fouilloux, V., Gran, C., Guervilly, C., Breaud, J., El Louali, F., \& Rostini, P. (2019). Impact of education and training course for ECMO patients based on high-fidelity simulation: A pilot study dedicated to ICU nurses. Perfusion, 34(1), 29-34. http://dx.doi.org/10.1177/0267659118789824

Garner, S., Van Dreven, A., MacDermott, S., \& Yates, M. (2018). Assessment and recency drive skill acquisition. The Clinical Teacher, 16, 232-235. http://dx.doi.org/10.1111/tct/12916

Hicks, F. D., Coke, L., \& Li, Suling. (2009, June). Findings from NCSBN Research Brief: The effect of high-fidelity simulation on nursing students' knowledge and performance: A pilot study (Issue brief No. 40).

Hoffert, D., Henshaw, C., \& Mvududu, N. (2007). Enhancing the ability of nursing students to perform a spiritual assessment. Nurse Educator 32(2), 66-72.

Kellogg Foundation, W. K. (2004). W. K. Kellogg Foundation logic model development guide. Retrieved from https://www.bttop.org/sites/default/files/public/W.K.\%20Kellogg\%20LogicModel .pdf

Kemper, K. J., Lynn, J., \& Mahan, J. D. (2018). What is the impact of online training in mind-body skills? Journal of Evidence-based Complementary \& Alternative Medicine, 20(4), 275-282. http://dx.doi.org/10.1177/2156587215580882

Labrague, L. J., McEnroe-Petitte, D. M., Bowling, A. M., Nwafor, C. E., \& Tsaras, K. (2018). High-fidelity simulation and nursing students' anxiety and self- 
confidence: A systematic review. Nursing Forum, 54, 358-368. http://dx.doi.org/10.1111/nuf.12337

Laerdal website: https://www.laerdal.com/us.products/simulation-training/nursing/(1) Morrison, A. M., \& Catanzaro, A. M. (2010). High-fidelity simulation and emergency preparedness. Public Health Nursing, 27(2), 164-173. http://dx.doi.org/10.1111/j.1525-1446.2010.00838.x

Phillips, J. L., Heneka, N., Hickman, L., Lam, L., \& Shaw, T. (2014). Impact of a novel online learning module on specialist palliative care nurses' pain assessment competencies and patients' reports of pain: Results from a quasi-experimental pilot study. Palliative Medicine, 28(6), 521-529.

http://dx.doi.org/120.1177/0269216314527780

Page, R. L. (2000). Brief history of flight simulation. SimTecT 2000 Proceedings, 11-17.

Raman, S., Labrague, L. J., Arulappan, J., Natarjan, J., Amirtharaj, A., \& Jacob, D. (2019). Traditional clinical training combined with high-fidelity simulation-based activities improves clinical competency and knowledge among nursing students on a maternity nursing course. Nursing Forum, 54, 434-440. http://dx.doi.org/10.1111/nuf.12351

Ross, M. C. (2010). Military nurse competencies. Nursing Clinics of North America, 45, 169-177. http://dx.doi.org/10.1016/j.cnur.2010.02.006

Venkatasalu, M. R., Kelleher, M., \& Shao, C. H. (2015). Reported clinical outcomes of high-fidelity simulation versus classroom-based end-of-life care education. International Journal of Palliative Nursing, 21(4), 179-186. http://dx.doi.org/10.12968/ijpn.2015.21.4.179 


\section{Appendix A}

\section{NCSBN Confidence Survey}

\begin{tabular}{|c|c|c|c|c|c|}
\hline & $\begin{array}{l}\text { Not at all } \\
\text { confident }\end{array}$ & $\begin{array}{c}\text { Somewhat } \\
\text { not confident }\end{array}$ & $\begin{array}{l}\text { Somewhat } \\
\text { confident }\end{array}$ & $\begin{array}{l}\text { Moderately } \\
\text { confident }\end{array}$ & $\begin{array}{l}\text { Very } \\
\text { confident }\end{array}$ \\
\hline $\begin{array}{l}\text { 1. How confident are you that you can recognize signs and } \\
\text { symptoms of a cardiac event? }\end{array}$ & 1 & 2 & 3 & 4 & 5 \\
\hline $\begin{array}{l}\text { 2. How confident are you that you can recognize signs and } \\
\text { symptoms of a respiratory event? }\end{array}$ & 1 & 2 & 3 & 4 & 5 \\
\hline $\begin{array}{l}\text { 3. How confident are you that you can recognize signs and } \\
\text { symptoms of a neurological event? }\end{array}$ & 1 & 2 & 3 & 4 & 5 \\
\hline $\begin{array}{l}\text { 4. How confident are you that you can accurately assess an } \\
\text { individual with chest pain? }\end{array}$ & 1 & 2 & 3 & 4 & 5 \\
\hline $\begin{array}{l}\text { 5. How confident are you that you can accurately assess an } \\
\text { individual with shortness of breath? }\end{array}$ & 1 & 2 & 3 & 4 & 5 \\
\hline $\begin{array}{l}\text { 6. How confident are you that you can accurately assess an } \\
\text { individual with changes in mental status? }\end{array}$ & 1 & 2 & 3 & 4 & 5 \\
\hline $\begin{array}{l}\text { 7. How confident are you that you can appropriately intervene for } \\
\text { an individual with chest pain? }\end{array}$ & 1 & 2 & 3 & 4 & 5 \\
\hline $\begin{array}{l}\text { 8. How confident are you that you can appropriately intervene for } \\
\text { an individual with shortness of breath? }\end{array}$ & 1 & 2 & 3 & 4 & 5 \\
\hline $\begin{array}{l}\text { 9. How confident are you that you can appropriately intervene for } \\
\text { an individual with changes in mental status? }\end{array}$ & 1 & 2 & 3 & 4 & 5 \\
\hline $\begin{array}{l}\text { 10. How confident are you that you can evaluate the effectiveness } \\
\text { of your interventions for an individual with chest pain? }\end{array}$ & 1 & 2 & 3 & 4 & 5 \\
\hline $\begin{array}{l}\text { 11. How confident are you that you can evaluate the effectiveness } \\
\text { of your interventions for an individual with shortness of breath? }\end{array}$ & 1 & 2 & 3 & 4 & 5 \\
\hline $\begin{array}{l}\text { 12. How confident are you that you can evaluate the } \\
\text { effectiveness of your interventions for an individual with } \\
\text { changes in mental status? }\end{array}$ & 1 & 2 & 3 & 4 & 5 \\
\hline
\end{tabular}

Note. Questionnaire is from the National Council of State Boards of Nursing, Inc. (NCSBN) 2009. 


\section{Appendix B}

Modified NCSBN Confidence Survey

\begin{tabular}{|c|c|c|c|c|c|}
\hline Survey Questions & $\begin{array}{l}\text { Not at all } \\
\text { confident }\end{array}$ & $\begin{array}{l}\text { Somewhat } \\
\text { not confident }\end{array}$ & $\begin{array}{l}\text { Somewhat } \\
\text { confident }\end{array}$ & $\begin{array}{l}\text { Moderately } \\
\text { confident }\end{array}$ & $\begin{array}{l}\text { Very } \\
\text { confident }\end{array}$ \\
\hline $\begin{array}{l}\text { 1. How confident are you that you can } \\
\text { recognize signs and symptoms of a stable } \\
\text { patient with a chest tube? }\end{array}$ & 1 & 2 & 3 & 4 & 5 \\
\hline $\begin{array}{l}\text { 2. How confident are you that you can } \\
\text { recognize signs and symptoms of a } \\
\text { patient with an air leak in their chest tube } \\
\text { management system? }\end{array}$ & 1 & 2 & 3 & 4 & 5 \\
\hline $\begin{array}{l}\text { 3. How confident are you that you can } \\
\text { recognize signs and symptoms of a } \\
\text { patient with a dislodged chest tube } \\
\text { management system? }\end{array}$ & 1 & 2 & 3 & 4 & 5 \\
\hline $\begin{array}{l}\text { 4. How confident are you that you can } \\
\text { recognize signs and symptoms of a } \\
\text { patient whose chest tube management } \\
\text { system has been knocked over? }\end{array}$ & 1 & 2 & 3 & 4 & 5 \\
\hline $\begin{array}{l}\text { 5. How confident are you that you can } \\
\text { appropriately intervene for a patient with } \\
\text { an air leak in their chest tube } \\
\text { management system? }\end{array}$ & 1 & 2 & 3 & 4 & 5 \\
\hline $\begin{array}{l}\text { 6. How confident are you that you can } \\
\text { appropriately intervene for a patient with } \\
\text { a dislodged chest tube? }\end{array}$ & 1 & 2 & 3 & 4 & 5 \\
\hline $\begin{array}{l}\text { 7. How confident are you that you can } \\
\text { appropriately intervene for a patient } \\
\text { whose chest tube management system } \\
\text { has been knocked over? }\end{array}$ & 1 & 2 & 3 & 4 & 5 \\
\hline $\begin{array}{l}\text { 8. How confident are you that you can } \\
\text { evaluate the effectiveness of your } \\
\text { interventions for a patient with an air leak } \\
\text { in their chest tube management system? }\end{array}$ & 1 & 2 & 3 & 4 & 5 \\
\hline $\begin{array}{l}\text { 9. How confident are you that you can } \\
\text { evaluate the effectiveness of your } \\
\text { interventions for a patient whose chest } \\
\text { tube has been dislodged? }\end{array}$ & 1 & 2 & 3 & 4 & 5 \\
\hline $\begin{array}{l}\text { 10. How confident are you that you can } \\
\text { evaluate the effectiveness of your } \\
\text { interventions for a patient whose chest } \\
\text { tube management system has been } \\
\text { knocked to the floor? }\end{array}$ & 1 & 2 & 3 & 4 & 5 \\
\hline
\end{tabular}

Note. Questionnaire is adapted from the National Council of State Boards of Nursing, Inc. (NCSBN) 2009. 


\section{Appendix C}

\section{Simulation Scenarios}

\section{Chest Tube Simulation Scenario \#1}

A simulated patient has been assigned to the nurse after placement of a chest tube for a hemothorax and pneumothorax on transport via Army helicopter for gunshot wound to right chest. The off-going nurse reports the patient has a right mid-axilla chest tube to a chest tube drainage system at negative $20 \mathrm{cmH} 2 \mathrm{O}$. Upon entering the room, the nurse will perform a lung assessment, vital signs, and an assessment of the chest tube drainage system based on the Elsevier training materials.

\section{Chest Tube Simulation Scenario \#2}

Simulated patient from scenario \#1 had developed continuous bubbling in the water seal chamber of the chest tube drainage system. The nurse will perform a lung assessment and vital signs on the patient, as well as assess the drainage system following the standards from the Elsevier training materials.

\section{Chest Tube Simulation Scenario \#3}

A simulated patient has been transferred to the ward from the post anesthesia recovery unit (PACU) after a video assisted thoracotomy procedure for removal of a lung nodule. The nurse is given report from the PACU staff that indicated a chest tube is in place and attached to a drainage system on of the right chest. The nurse enters the room and after the patient is transferred from a stretcher to his bed and the chest tube has become dislodged. The nurse will perform an airway and breathing assessment, as well as interventions discussed in the pre-briefing.

\section{Chest Tube Simulation Scenario \#4}

The simulated patient from scenario \#3 has had his chest tube replaced during the night shift. The nurse again assumes care of the patient and discovers the chest tube drainage system has been knocked to the floor with the water seal chamber breached and the drainage chambers pouring into one another. The nurse will perform and airway and breathing assessment, assessment of the equipment, and perform interventions discussed in the pre-briefing. 


\section{Appendix D}

\section{Chest Tube Management Pre-Briefing}

LCDR James Jeff

Adult/Gerontology Acute Care CNS Student

Rhode Island College

\section{DRAINAGE SYSTEM}

•change when system is full or damaged

-monitor patient for change in spo2 during change

-have new system set up and ready before clamping

-change should take less than one minute

\section{MAINTENANCE}

-avoid dependent loops (place tube horizontally on bed)

-if unable to avoid (transport etc.) ensure tube drained several times per hour

-ensure float or baffle are in designated box per system manufacturer

-20 cm h2o or "water seal" per order

\section{MONITORING \& CARE}

-after placement RN should monitor vital signs q15mins until provider determines he is stable then q2 hours or per unit policy/order

-monitor type of drainage and amount hourly (may need to be more frequent if recent surgery or penetrating chest trauma) $>100-150 \mathrm{ml}$ for two consecutive 15 -min periods may indicate hemorrhage depending on procedure

-small amount of bubbling may be present after placement for pneumothorax

-tidaling is normal with breathing; may be altered with positive pressure ventilation -ensure leg support is deployed when stationary 


\section{TRANSPORT}

-ensure suction is continued with portable suction of so ordered by provider

-obtain order for transport via water seal

-do not clamp unless ordered to do so

•maintain system below patient to avoid backflow

-secure tubing to chest distal to chest tube site to prevent dislodging tube

\section{IF A LEAK IS PRESENT}

-ensure tube is not visibly dislodged or eyelet is exposed

-intermittently occlude the chest tube for less than a minute

-start at insertion site and work towards drainage system

- observe for signs of respiratory distress and stop immediately if signs appear

-inform provider of location for replacement or tape to secure leak

\section{AIR LEAK TROUBLESHOOTING}

•turn off suction (temporarily)

-ask the patient to take deep breaths

-check all connections

-if bubble persists; begin clamping at intervals along length of tubing

-when the bubble stops the air leak is between the clamp and patient

•***if bubbling is continuous it may indicate leak in the drainage system***

\section{SYSTEM ISSUES}

-tube becomes dislodged form system; submerge in sterile water until new system setup. only clamp if no water available

-system kicked over or damaged should be replaced for accurate measurement and proper water seal 


\section{CHEST TUBE DISLODGEMENT}

-quickly seal site with sterile petroleum gauze to prevent outside air from entering pleural space.

•notify provider immediately

-prepare for reinsertion and/or chest x-ray

-monitor patient and apply o2 as needed

\section{BEDSIDE NECESSITIES FOR PATIENT WITH CHEST TUBE}

•petroleum gauze

-bottle of sterile water/ns

-4x4 gauze

-tape

-padded clamps (new systems have clamp)

-extra water seal system available 